\title{
Life-Cycle Analysis and Evaluation of Mechanical Properties of a Bio-Based Structural Adhesive
}

\author{
Konstantinos Tserpes *(D) and Vasileios Tzatzadakis
}

check for

updates

Citation: Tserpes, K.; Tzatzadakis, V. Life-Cycle Analysis and Evaluation of Mechanical Properties of a Bio-Based Structural Adhesive. Aerospace 2022, 9, 64. https:// doi.org/10.3390/aerospace 9020064

Academic Editor: Khamis Essa

Received: 15 December 2021

Accepted: 20 January 2022

Published: 25 January 2022

Publisher's Note: MDPI stays neutral with regard to jurisdictional claims in published maps and institutional affiliations.

Copyright: (c) 2022 by the authors. Licensee MDPI, Basel, Switzerland. This article is an open access article distributed under the terms and conditions of the Creative Commons Attribution (CC BY) license (https:// creativecommons.org/licenses/by/ $4.0 /)$.
Laboratory of Technology \& Strength of Materials, Department of Mechanical Engineering \& Aeronautics, University of Patras, 26500 Patras, Greece; vasileios.tzatzadakis@upnet.gr

* Correspondence: kitserpes@upatras.gr

\begin{abstract}
For this present paper, we performed a life-cycle analysis and an evaluation of the mechanical properties of an epichlorohydrin/cardanol adhesive in a neat and a nano-filled form. Six different potentials and the cost of the adhesives were derived and compared with those of a commercial epoxy resin. Overall, the neat adhesive was found to be more environmentally friendly and to have a lower production cost. However, the addition of carbon nanotubes increased both the environmental footprint and the cost. The evaluation with regards to the mechanical properties was performed through a comparison of bulk properties and joint properties with the respective average values of commonly used structural and nonstructural adhesives from the literature. It was found that for all properties except for the Young's modulus the novel adhesive had values greater than the average values of the cosmetic adhesives and for most properties it had values close to the average values of the structural adhesives. Moreover, the presence of the carbon nanotubes enhanced the mechanical properties of the adhesive except for the tensile strength.
\end{abstract}

Keywords: bio-based adhesive; life-cycle analysis; cost analysis; mechanical characterization

\section{Introduction}

In the last decades, the application of bio-based polymers in the form of bulk materials, matrix and adhesives has been expanding very fast in the aerospace [1-3] and the automotive industries [4]. On the other hand, as the bioeconomy is thriving, bio-based products are used progressively in numerus applications in various fields and draw the attention of the researchers. Natural resource-based polymers are still a small fraction of the overall global plastics market. Nevertheless, the global interest in biomass-based polymers has grown in recent years due to the need of the industry to be independent from fossil fuels.

Several studies have been conducted in the past on the environmental impact of epoxy resins [5-7]. The environmental issue that arises is the environmental cost that is incurred during their production. The life cycle analysis of an epoxy resin is based on the production of the resin itself. This is because, after the curing process of an epoxy adhesive, the resin is inactivated and can be characterized as a typical plastic. Like any other curable epoxy resin, bio-based adhesives cannot be reused. Thermosetting resins, like the epichlorohydrin/cardanol adhesive, cannot be remolded and used in the same way again. After their service life, epoxy resins and adhesives usually do not find themselves useful in a compelling application [8].

The most typical and frequent way to reuse cured epoxy resins is through body recycling. This means that a cured epoxy resin body (which may be a composite material or part of a plastic body) is pulverized or crushed and that it can be used as reinforcement or as an additive to create a new structure [9]. This technique could be applied in the production of asphalt, concrete, construction of composite materials, furniture, or construction of plastic structures such as trash cans, mailboxes, etc.

Efforts are recently being made to break down and recover the monomers that make up an epoxy resin, once it has been hardened, by various chemical treatments [10-12]. 
However, the most promising technique is that of the extensive hydrolysis [13,14], in which no chemicals harmful to humans and the environment are used. In this way it is possible to recover the monomers of an epoxy resin and reuse them. It is therefore vital to compare the environmental impacts of the production of an epoxy petroleum-based resin (as a reference resin) with the environmental impacts of the production of a bio-based resin (epichlorohydrin/cardanol adhesive) in order to draw conclusions about the environmental impact of the novel bio-based adhesive.

In the literature, no significant works have been reported on the synthesis and production of bio-based structural adhesives. This is mainly due to the evidence that the mechanical properties of bio-based adhesives degrade when exposed to a humid environment [15]. Most of the existing bio-based adhesives are destined to medical applications and usually are biodegradable and biocompatible. Research on bio-based structural adhesives is focused on the development of soya-based adhesives for wood applications [15-18]. Lignin, starch, cellulose, and natural oils have been also used for the production and reinforcement of bio-based adhesives. Ceseracciu [19] suggested the development of biodegradable elastomers and adhesives using starch. Khanjanzadeh [20] used lignin and cellulose for reinforcing a wood adhesive. Scarica [21] synthesized a layered adhesive using lignin. Finally, a series of efforts have been reported [22-24] to synthesize adhesives from natural oils. However, the produced materials are not totally bio-based and they do not have the required properties.

In [25], the authors of the present paper produced and characterized a novel bio-based adhesive made from epichlorohydrin and cardanol. The main sources of epichlorohydrin are propylene and glycerin. Since glycerin is plant-based, the production of epichlorohydrin from glycerin (or glycerol) is cost-efficient and also environmentally friendly. The glycerin to epichlorohydrin process is more energy-efficient, due to simpler chemical procedures, and there are no hazardous wastes to deal with. Cardanol is a chemical compound produced from anacardic acid, which is found in the cashew nutshell liquid. Given that the bio-based polymers are prone to environmental conditions, in [26], the effects of hygrothermal ageing on the mechanical properties of the epichlorohydrin/cardanol adhesive have been characterized experimentally by subjecting bulk specimens and bonded joints to the conditions of $70{ }^{\circ} \mathrm{C} / \mathrm{RH} 85 \%$ until saturation and then testing them mechanically. It was found that the epichlorohydrin/cardanol adhesive is prone to hygrothermal ageing since its bulk properties are considerably decreased. However, this is not the case for the shear strength measured from single-lap shear tests on aged, bonded specimens. In [27], the epichlorohydrin/cardanol adhesive was filled by multiwalled carbon nanotubes (CNTs) aiming to enhance its mechanical properties, thus making it more suitable for structural applications. The reinforcement efficiency was tested by means of dynamical mechanical analysis (DMA) tests, tension tests, fracture toughness tests on bulk specimens and singlelap shear (SLS) tests on bonded specimens. The morphology of the CNT-filled adhesive was characterized by scanning electron microscopy (SEM) tests. The results from the tests show that the presence of the CNTs increases the glass transition temperature, the Young's modulus and the fracture toughness of the reinforced bio-based adhesive, while it decreases its tensile strength.

For the present paper, we performed a life cycle analysis (LCA) by evaluating the environmental impact from the production of the bio-based adhesive through the consideration of six key impact categories, namely the abiotic depletion potential (ADP), the acidification potential (AP), the eutrophication potential (EP), the ozone depletion potential (ODP), the photochemical ozone creation potential (POCP), and the global warming potential (GWP) and we derived the production cost of the bulk adhesive and of adhesive joints. In addition, we evaluated the mechanical properties of the bio-based adhesive by using definitions of "structural adhesives" from the literature and by comparison with average properties of a series of widely used cosmetic and structural adhesives. 


\section{Materials}

The bio-based adhesive was synthesized using three components, an epoxy resin, an epoxy hardener, and an epoxy diluent. The epoxy resin was based on epichlorohydrin, which was produced from plant-based glycerin. The trade name of the epoxy resin is EnviPOXY 530 (Spolchemie, Ústí nad Labem, Czech Republic) [28]. EnviPOXY 530 resin is environmentally friendly with a very high recyclable content. The hydrochloric acid $(\mathrm{HCl})$ content is less than $0.03 \%$. It does not contain any modifiers (to optimize its properties) and has received an environmental product declaration (EPD). The cardanol hardener used to make the adhesive is branded as NX-2003. The hardener NX-2003 (Cardolite Co., Cardolite, Belgium) does not contain traces of solvents and benzyl alcohol and is a purely phenalkamine hardener. The epoxy based cardanol solvent used to make the adhesive is branded as NC-513 (Cardolite Co., Belgium). It was used in the production of the adhesive in order to make it more flexible. The solvent does not contain solvents.

\section{Methodologies}

\subsection{Overview of Mechanical Testing}

The neat adhesive and the MWCNT-doped adhesive were experimentally characterized in [25] and [27], respectively, by conducting a series of mechanical tests. Specifically, the bulk properties of the adhesives were measured by tension tests which were conducted according to the ASTM D638-14 standard, Mode-I fracture toughness tests which were conducted according to the ASTM D5045-14 standard, and dynamic mechanical analysis (DMA) tests, whereas the joining properties of the adhesives were measured by singlelap shear (SLS) tests comprised from aluminum and composite adherends which were conducted according to the ASTM D5868-01 standard. The average experimental values from these tests will be presented in the comparison made with respective values from the literature in Section 4.2.

\section{2. $L C A$}

This study evaluates the environmental impact of the epichlorohydrin/cardanol adhesive on the basis of a comparison with a reference epoxy resin for which data were taken from [5]. The environmental impact of carbon nanotubes on the $\mathrm{CO}_{2}$ growth and global warming potential is also considered. An important parameter for the future use of bio-based epoxy resins is their production cost, compared to an epoxy resin from fossil fuels. In the present analysis, the production cost of the bio-based adhesive and the nano-reinforced adhesive were calculated and compared to that of the epoxy reference resin from [5]. The environmental data for the EnviPOXY 530 epoxy resin were obtained from Spolchemie's environmental impact research [28], while the data on the NC-513 epoxy solvent and NX-2003 hardener were provided by Cardolite Co. The calculation of the environmental potentials was performed according to the ISO 14025: 2006 [29] and ISO 14,040 [30] standards for the EnviPOXY 530 epoxy resin and the NC-513 epoxy solvent, while for the NX-2003 hardener according to the standard. ISO 14,040 [30].

To summarize, all data for the LCA and the cost analysis for the neat bio-based adhesive and the CNT-filled bio-based adhesive were drawn from [28] and Cardolite Co., while the data for the reference epoxy resin from [5].

The environmental potentials of the epichlorohydrin/cardanol adhesive were calculated using the following equation:

$$
\Delta_{i}=\left(k \cdot P_{i}\right)+\left(r \cdot \Sigma_{i}\right)+\left(d \cdot E_{i}\right) 0<k, r, d<1
$$

where $\Delta_{i}$ is the environmental potential of the bio-based adhesive, $k$ is the content of the epoxy resin EnviPOXY 530 in the adhesive mixture, $P_{i}$ is the environmental potential of the epoxy resin, $r$ is the hardener content of NX-2003 in the mixture, $\Sigma_{i}$ is the environmental potential of the hardener, $d$ is the epoxy solvent content of NC-513 in the adhesive mixture, 
and $E_{i}$ is the environmental potential of the epoxy solvent. The values of the parameters of Equation (1) are listed in Tables 1-5.

Table 1. Parameter values of the abiotic depletion potential.

\begin{tabular}{|c|c|c|}
\hline Parameter & \multicolumn{2}{|c|}{ Value 1} \\
\hline K & \multicolumn{2}{|c|}{0.55} \\
\hline$P_{1}$ & $1.02 \times 10^{-5} \mathrm{~kg} \mathrm{Sb}-\mathrm{Eq}$ & 87.7 MJ \\
\hline$R$ & \multicolumn{2}{|c|}{0.31} \\
\hline$\Sigma_{1}$ & $1.47 \times 10^{-7} \mathrm{~kg} \mathrm{Sb}-\mathrm{Eq}$ & $7.24 \mathrm{~kg} \mathrm{Sb}-\mathrm{Eq}$ \\
\hline$d$ & \multicolumn{2}{|c|}{0.13} \\
\hline$E_{1}$ & $3.85 \times 10^{-7} \mathrm{~kg} \mathrm{Sb}-\mathrm{Eq}$ & $19.5 \mathrm{~kg} \mathrm{Sb}-\mathrm{Eq}$ \\
\hline
\end{tabular}

Table 2. Parameter values of the acidification.

\begin{tabular}{cc}
\hline Parameter & Value 2 \\
\hline$k$ & 0.55 \\
\hline$P_{2}$ & $2.08 \times 10^{-2} \mathrm{~kg} \mathrm{SO}$-eq \\
\hline$r$ & 0.31 \\
\hline$\Sigma_{2}$ & $3.53 \times 10^{-3} \mathrm{~kg} \mathrm{SO} 2$-eq \\
\hline$d$ & 0.13 \\
\hline$E_{2}$ & $8.94 \times 10^{-4} \mathrm{~kg} \mathrm{SO} 2$-eq \\
\hline
\end{tabular}

Table 3. Parameter values of the eutrophication potential.

\begin{tabular}{cc}
\hline Parameter & Value 3 \\
\hline$k$ & 0.55 \\
\hline$P_{3}$ & $1.29 \times 10^{-2} \mathrm{~kg}$ Phosphate-eq \\
\hline$r$ & 0.31 \\
\hline$\Sigma_{3}$ & $1.47 \times 10^{-3} \mathrm{~kg}$ Phosphate-eq \\
\hline$d$ & 0.13 \\
\hline$E_{3}$ & $2.84 \times 10^{-3} \mathrm{~kg}$ Phosphate-eq \\
\hline
\end{tabular}

Table 4. Parameter values of the ozone depletion potential.

\begin{tabular}{cc}
\hline Parameter & Value 4 \\
\hline$k$ & 0.55 \\
\hline$P_{4}$ & $1.93 \times 10^{-7} \mathrm{~kg} \mathrm{CFC11-eq}$ \\
\hline$r$ & 0.31 \\
\hline$\Sigma_{4}$ & $4.12 \times 10^{-8} \mathrm{~kg} \mathrm{CFC11-eq}$ \\
\hline$d$ & 0.13 \\
\hline$E_{4}$ & $1.05 \times 10^{-7} \mathrm{~kg} \mathrm{CFC11-eq}$
\end{tabular}


Table 5. Parameter values of the photochemical ozone creation potential.

\begin{tabular}{cc}
\hline Parameter & Value 5 \\
\hline$k$ & 0.55 \\
\hline$P_{5}$ & $1.52 \times 10^{-2} \mathrm{~kg}$ ethene-Eq \\
\hline$r$ & 0.31 \\
\hline$\Sigma_{5}$ & $1.38 \times 10^{-4} \mathrm{~kg}$ ethene-Eq \\
\hline$d$ & 0.13 \\
\hline$E_{5}$ & $1.05 \times 10^{-4} \mathrm{~kg}$ ethene-Eq \\
\hline
\end{tabular}

For the purpose of this research and the study of the environmental impact of the nano-reinforced resin, results from the literature were used. In particular, for the carbon dioxide emissions for carbon nanotubes, the data of carbon nanofibers were used as they have a similar method of preparation and similar environmental effects [31-34].

The global warming potential of the nano-reinforced epichlorohydrin/cardanol adhesive was calculated as a function of its components according to the following equation:

$$
\Delta_{6}=\left(k \cdot P_{6}\right)+\left(r \cdot \Sigma_{6}\right)+\left(d \cdot E_{6}\right)+(v \cdot N) 0<k, r, d<1
$$

where $\Delta_{6}$ is the global warming potential, $k$ is the epoxy resin content of EnviPOXY 530 in the adhesive mixture, $P_{6}$ is the global warming potential of the epoxy resin, $r$ is the NX-2003 hardener content in the adhesive mixture, $\Sigma_{6}$ is the global warming potential of the hardener, $d$ is the content of epoxy solvent NC-513 in the adhesive mixture, $E_{6}$ is the global warming potential of the epoxy solvent, $v$ is the carbon nanotube content in the adhesive, and $N$ is global warming potential of carbon nanotubes. The values of the parameters of Equation (2) are given in Table 6.

Table 6. Parameter values of the global warming potential.

\begin{tabular}{|c|c|c|c|}
\hline Parameter & & Value 6 & \\
\hline$k$ & & 0.55 & \\
\hline$P_{6}$ & & 5.14 & \\
\hline$r$ & & 0.31 & \\
\hline$\Sigma_{6}$ & & -2.31 & \\
\hline$d$ & & 0.13 & \\
\hline$E_{6}$ & & -1.11 & \\
\hline$v$ & $0.5 \%$ & $1 \%$ & $2 \%$ \\
\hline$N$ & & $6.80 \mathrm{E}+02$ & \\
\hline
\end{tabular}

\subsection{Production Cost}

An important parameter for the extensive use of the bio-based adhesive is the production cost compared to a common epoxy resin. The production cost of the adhesive is a function of the energy used to produce it. The cost of $1 \mathrm{kWh}$ can be considered equal to 0.114 euros [35]. The energy of adhesive's production in $\mathrm{kWh}$ can be considered equal to $0.34 \mathrm{~kg} \mathrm{CO} / \mathrm{kWh}$ [24]. Based on the global warming potential in $\mathrm{kg} \mathrm{CO}_{2}$ emissions, the production cost of the reference epoxy resin was calculated compared to the bio-based one according to the following equation:

$$
\begin{aligned}
& K=E \cdot K_{K} \\
& G W P_{100}=E \cdot \frac{m C O_{2 e q}}{k W h}
\end{aligned}
$$


where $K$ is the cost of production of an epoxy resin per kilo, $E$ is the $\mathrm{kWh} / \mathrm{kg}$ of resin produced, $K_{K}$ is the cost of one $\mathrm{kWh}, \mathrm{GWP} 100$ is the global warming potential of epoxy resin, $m \mathrm{CO}_{2} e q / k W h$ is the mass of the carbon dioxide to produce one $\mathrm{kWh}$.

The cost of producing aluminum joints per kilo of bio-based adhesive was studied. The cost of producing aluminum adhesives with the adhesive was compared to the reinforced carbon nanotube adhesive.

The cost of the joints is related to the process in man-hours and the cost of materials used. The cost of one hour of work was considered $27.7 € / h$ [36], the average price of the European Union. The cost of the materials used is listed in Table 7 and the cost of the procedure is shown in the following equation:

$$
K_{S}=K_{m}+k \cdot K_{L}
$$

where $K_{S}$ is the cost of producing the joints, $K_{m}$ is the cost of materials, $k$ is the labor rate in hours, $K_{L}$ is the cost of one man-hour.

Table 7. Cost of materials.

\begin{tabular}{cc}
\hline Materials & Cost $(\boldsymbol{€} / \mathbf{k g})$ \\
\hline NaOH & 30 \\
\hline Phosphoric acid & 50 \\
\hline Deionized water & 2 \\
\hline CNTs & 700 \\
\hline
\end{tabular}

\subsection{Evaluation of Mechanical Properties}

In the second part of the study, the mechanical properties of the bio-based adhesive were evaluated aiming to assess the suitability of the adhesive for cosmetic and structural applications. According to Bernd Burchard [37], "a structural adhesive can be defined as any adhesive that meets the requirements for its application and use in a specific component". Therefore, it is up to the engineer to use any adhesive as a structural adhesive, solely on the basis of the ability of the adhesive to carry the loads that may develop in the joint. Hollaway [38] lists some of the characteristics which an epoxy structural adhesive should theoretically has. According to his research, if an epoxy adhesive is within these limits, it could be characterized as an adhesive for structural applications.

Usually, the mechanical behavior of an adhesive is usually characterized by the modulus of elasticity, the tensile strength, the fracture toughness and the shear strength of the adhesive (shear strength could be calculated from metal or composite material joints). Another important factor for the evaluation of a structural adhesive is its thermomechanical properties. The glass transition temperature $\left(T_{g}\right)$ of a structural adhesive is a basic indication of the operating temperature range of the adhesive. All these properties have been evaluated for the neat and nano-filled bio-based in [12] and [14], respectively.

For the sake of completeness of the paper, the following tables are presented with the basic properties of some commercial adhesives, so that during the evaluation of the properties of the bio-based adhesive, to enable comparison with the available adhesives. Table 8 lists the tensile strength and glass transition temperature of the structural adhesives [39-41], Table 9 lists the fracture toughness of the structural adhesives and Table 10 lists the shear strength of the structural adhesives [39-41]. The average value for the Young's modulus of commercial structural adhesives was estimated at 3.45 GPa [39-41]. 
Table 8. Tensile strength and glass transition temperature of structural adhesives.

\begin{tabular}{ccc}
\hline Structural Adhesive & Tensile Strength (MPa) & Glass Transition Temperature $\left(\mathbf{C}^{\circ}\right)$ \\
\hline AV 8504 & 50.33 & 130.0 \\
\hline EPI 200 & 51.71 & 55.30 \\
\hline EPI 300 & 53.78 & 70.00 \\
\hline EA 9309 & 32.20 & 61.00 \\
\hline EA9330 & 38.60 & 57.00 \\
\hline EA 9330.3 & 42.00 & 54.00 \\
\hline EA 9395 & 55.60 & 73.00 \\
\hline EA960F & 15.20 & 66.00 \\
\hline EA 9309NA & 31.00 & 53.00 \\
\hline EA 9394S & 46.00 & 78.00 \\
\hline EA 9309.2 & 37.20 & 79.00 \\
\hline Mean Value: & 41.24 & 70.57 \\
\hline
\end{tabular}

Table 9. Fracture toughness of structural adhesives.

\begin{tabular}{cc}
\hline Structural Adhesive & $\boldsymbol{K}_{\text {IC }}\left(\mathbf{M P a} \cdot \mathbf{m}^{\mathbf{1} \mathbf{2}}\right)$ \\
\hline MY750 & 1.254 \\
\hline CY 230/HY 951 & 1.028 \\
\hline Epon828/Dicyandiamide & 1.220 \\
\hline W635/EC57 & 1.190 \\
\hline EC57 Elantas ${ }^{\circledR}$ Camattini & 1.200 \\
\hline Epon828 & 2.170 \\
\hline Mean Value: & 1.34 \\
\hline
\end{tabular}

Table 10. Lap shear strength of structural adhesives.

\begin{tabular}{|c|c|}
\hline Structural Adhesive & Lap Shear Strength (MPa) \\
\hline AV 8504 & 12.76 \\
\hline EPI 100 & 34.47 \\
\hline EPI 1210/9615 & 17.24 \\
\hline EPI 1210/9861 & 19.31 \\
\hline EPI 1217 & 17.24 \\
\hline EPI 1534 & 20.68 \\
\hline EPI 1544 & 17.93 \\
\hline EPI 1559 & 18.62 \\
\hline EPI 1565 & 6.89 \\
\hline EPI 200 & 19.10 \\
\hline EPI 300 & 28.96 \\
\hline EPI 8000 & 26.89 \\
\hline EPI 8543 & 13.79 \\
\hline FAST 10 & 19.31 \\
\hline EA 9309,3 & 38.00 \\
\hline EA9330 & 34.50 \\
\hline
\end{tabular}


Table 10. Cont.

\begin{tabular}{cc}
\hline Structural Adhesive & Lap Shear Strength (MPa) \\
\hline EA 9330,3 & 39.30 \\
\hline EA 9395 & 29.70 \\
\hline EA960F & 15.20 \\
\hline EA 9359,3 & 31.00 \\
\hline EA 9394 & 28.90 \\
\hline Mean Value: & 23.32 \\
\hline
\end{tabular}

An attempt was also made to determine the typical mechanical properties of an adhesive for nonstructural applications, which are admittedly weaker than those used for structural applications in the automotive and aerospace industries. Tables 11-15 show typical property values of adhesives for nonstructural applications provided by Huntsman International LLC [39] and Henkel Corporation [40].

Table 11. Young's modulus of nonstructural adhesives.

\begin{tabular}{cc}
\hline Nonstructural Adhesive & Young's Modulus (GPa) \\
\hline AW 136H/HY991 & 2.1 \\
\hline E-05CL HYSOL & 1.9 \\
\hline Araldite $^{\circledR}$ LY 564 & 2.1 \\
\hline Mean Value: & 2.0 \\
\hline
\end{tabular}

Table 12. Tensile strength of nonstructural adhesives.

\begin{tabular}{cc}
\hline Nonstructural Adhesive & Tensile Strength (MPa) \\
\hline AW 136H/HY991 & 42 \\
\hline E-00NS HYSOL & 12 \\
\hline E-90FL HYSOL & 13 \\
\hline Mean Value: & 22 \\
\hline
\end{tabular}

Table 13. Glass transition temperature of nonstructural adhesives.

\begin{tabular}{cc}
\hline Nonstructural Adhesive & Glass Transition Temperature $\left(\mathbf{C}^{\circ}\right)$ \\
\hline AW 136H/HY991 & 55 \\
\hline E-00NS HYSOL & 35 \\
\hline E-90FL HYSOL & 30 \\
\hline Mean Value: & 40 \\
\hline
\end{tabular}

Table 14. Fracture toughness of nonstructural adhesives.

\begin{tabular}{ccc}
\hline Nonstructural Adhesive & $\boldsymbol{K}_{I C}\left(\mathbf{M P a} \cdot \mathbf{m}^{\mathbf{1 / 2}}\right)$ & Reference \\
\hline DER 661 & 0.57 & 30 \\
\hline RTM6 & 0.61 & 31 \\
\hline Araldite $^{\circledR}$ LY 564 & 0.68 & 32 \\
\hline Epikote 828/HD-Acc43 & 1.52 & 33 \\
\hline Epikote 828/HN-2200R & 2.77 & 33 \\
\hline Mean Value: & 1.23 & \\
\hline
\end{tabular}


Table 15. Lap shear strength of nonstructural adhesives.

\begin{tabular}{cc}
\hline Nonstructural Adhesive & Lap Shear Strength (MPa) \\
\hline AW 136H/HY991 & 13 \\
\hline AY105-1/HY998 & 14 \\
\hline E-00NS HYSOL & 11 \\
\hline 3035 & 2.5 \\
\hline E-90FL HYSOL & 5.5 \\
\hline Mean Value: & 9.2 \\
\hline
\end{tabular}

\section{Results}

\subsection{Results of the LCA}

Figures 1-8 compare the ADP, the AP, the EP, the ODP, the POCP, and the GWP of the epichlorohydrin/cardanol adhesive with those of the reference epoxy resin. The ADP is reduced by $267 \%$ in terms of equivalent amount of antimony (Figure $1 \mathrm{a}$ ) and by $176 \%$ in terms of energy (Figure 1b). The AP is reduced by 204\% in terms of equivalent amount of $\mathrm{SO}_{2}$ (Figure 2). The EP is increased by $44 \%$ in terms of equivalent amount of $\mathrm{PO}_{3}$ (Figure 3). The ODP is reduced by $275 \%$ in terms of equivalent amount of CFC-11 (Figure 4 ). The POCP is increased by $185 \%$ in terms of equivalent amount of $\mathrm{C}_{2} \mathrm{H}_{4}$ (Figure 5). The GWP of the neat bio-based adhesive is decreased by $345 \%$ in terms of $\mathrm{CO}_{2}$ emissions but when the bio-based adhesive is filled by CNTs its GWP increases. For $0.5 \mathrm{wt} \% \mathrm{CNTs}$, the GWP increase by $174 \%$ compared to that of the neat bio-based and for $2 \mathrm{wt} \%$ CNTs by $694 \%$, which is $349 \%$ above the GWP of the reference resin.
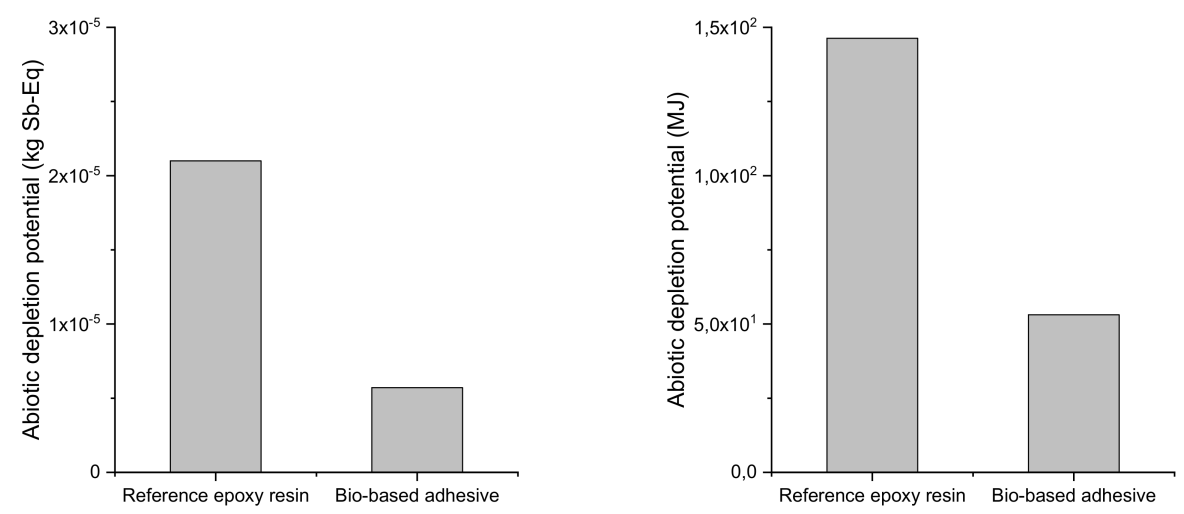

(a)

Figure 1. Comparison of ADP (a) kg-Sb-Eq, (b) MJ.

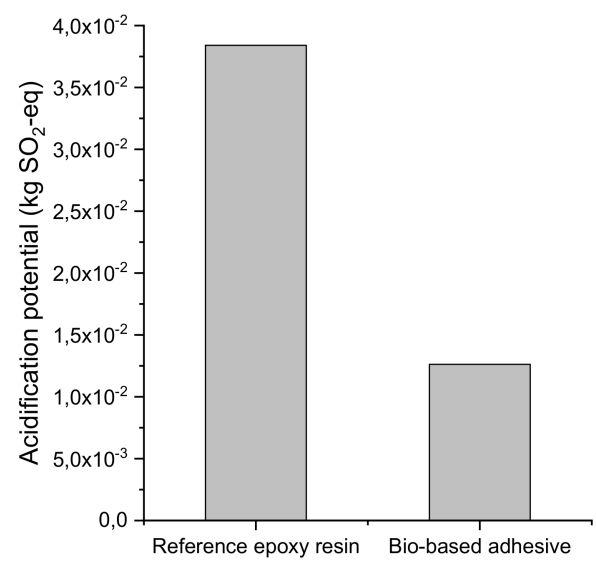

Figure 2. Comparison of $\mathrm{AP}$ in terms of equivalent amount of $\mathrm{SO}_{2}$. 


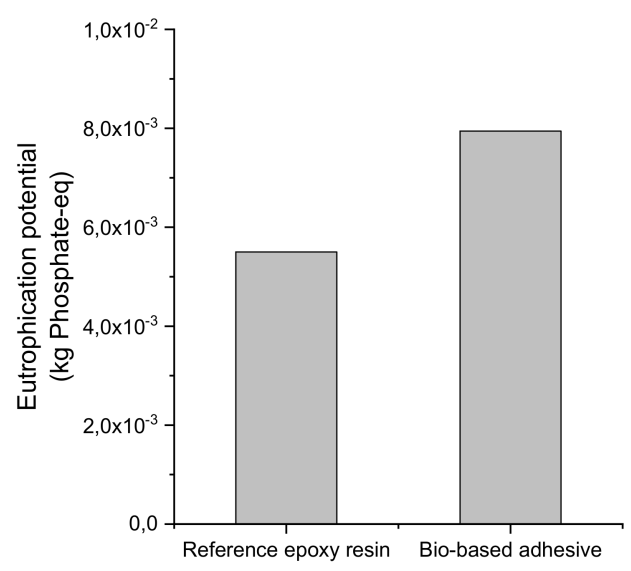

Figure 3. Comparison of EP in terms of equivalent amount of $\mathrm{PO}_{3}$.

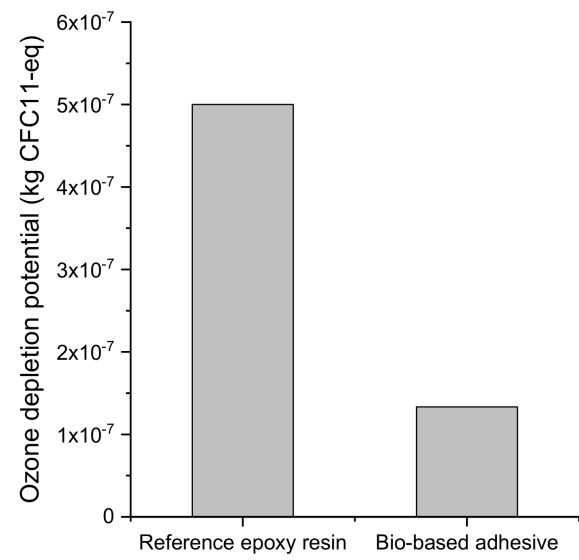

Figure 4. Comparison of ODP in terms of equivalent amount of CFC-11.

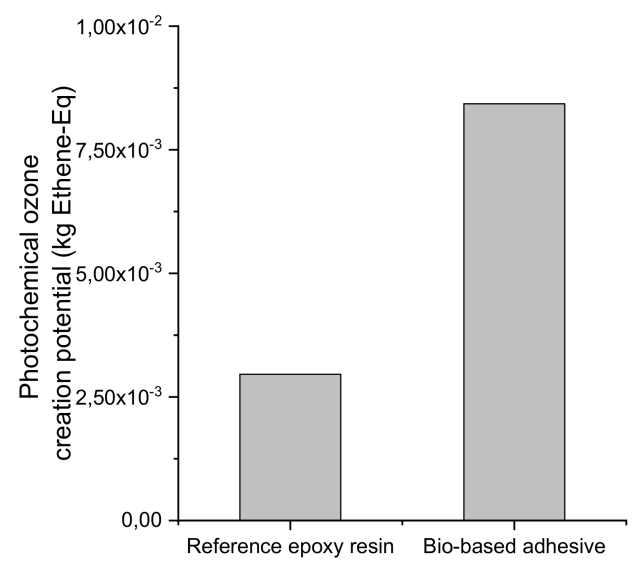

Figure 5. Comparison of POCP in terms of equivalent amount of $\mathrm{C}_{2} \mathrm{H}_{4}$.

As shown in Figure 8, the production cost of the bio-based adhesive $(0.65 € / \mathrm{kg})$ is lower by $77 \%$ than the production cost of the reference resin $(2.9 € / \mathrm{kg})$. Furthermore, Figure 9 compares the production cost of the aluminum adhesive joints bonded with the neat, the nano-filled bio-based adhesive and the reference epoxy resin. As can be seen, whereas the joints bonded with the neat bio-based adhesive has a lower cost than the joints bonded with the reference epoxy resin, the addition of CNTs increases the cost of the joints significantly. With increasing the content of the CNTs from 0.5 to $2 \%$, the production cost of the aluminum joints compared to the cost of the reference epoxy resin increases from 44 to $51 \%$. The deviation in the comparison of the cost of materials (Figure 8) and the cost of the joints (Figure 9) is attributed to the application cost. Specifically, there is an increased cost 
in the production of the joints in the present work compared to [5] due to the low degree of automation, and the higher application of human-driven processes.

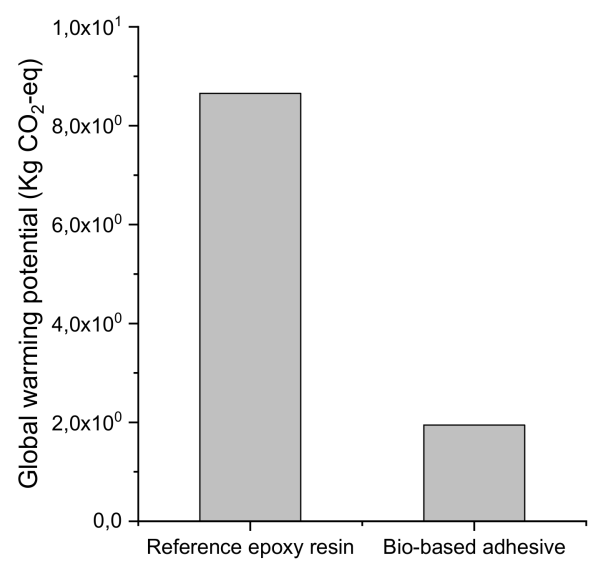

Figure 6. Comparison of GWP between the neat bio-based adhesive and the reference epoxy in terms of $\mathrm{CO}_{2}$ emissions.

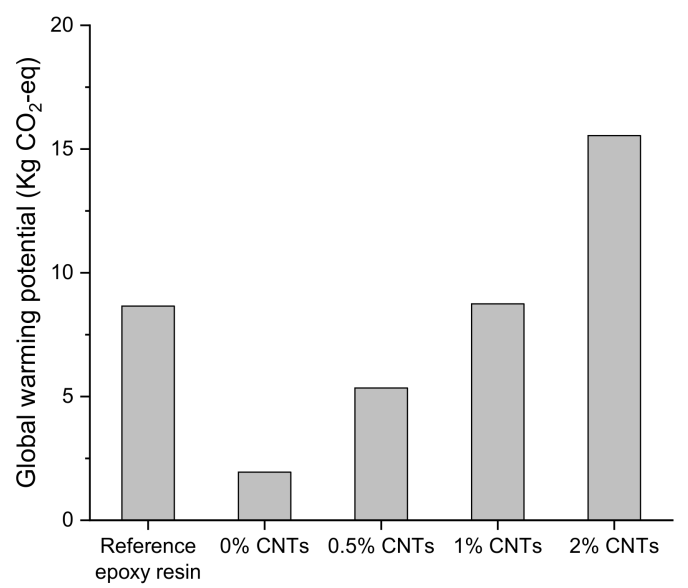

Figure 7. Comparison of the GWP between the neat, the nano-filled bio-based adhesive and the reference epoxy in terms of $\mathrm{CO}_{2}$ emissions.

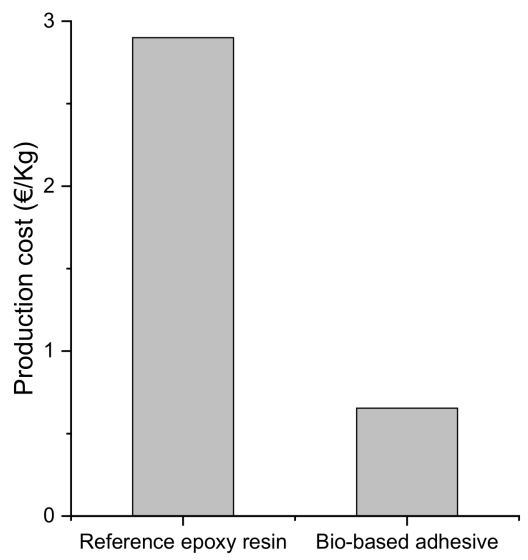

Figure 8. Comparison of the production cost of the bio-based adhesive and the reference epoxy resin. 


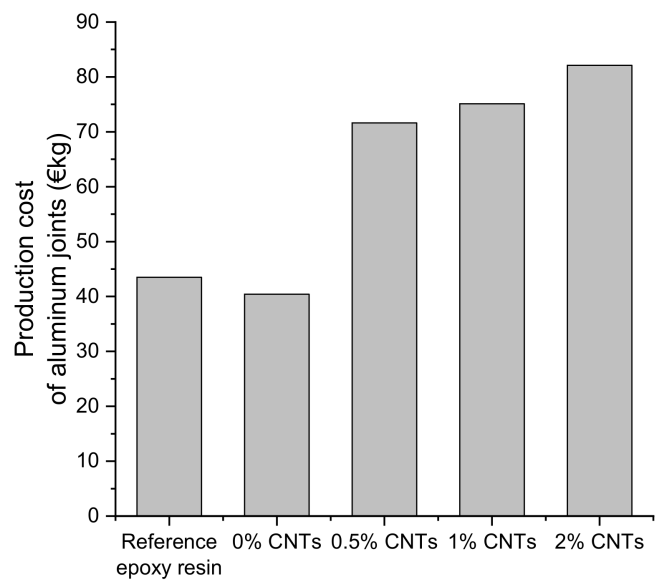

Figure 9. Comparison of the production cost of the adhesive joints bonded with the neat, the nano-filled and the reference epoxy resin.

Although a direct comparison of the present LCA findings with similar findings from would be very useful, this is not possible due to the lack of data in the literature. Among the few existing works on LCA of bioadhesives, the two most representative are presented in brief in the next paragraph.

McDevitt and Grigsby [42] have used LCA to compare the impact of two adhesive systems used for a medium density fiberboard. Adhesives made from a theoretical proteinlignin-composite and petrochemical feedstocks were investigated. Eco-indicator 99, a single score sustainability impact assessment method was applied. The calculations reveal that the bioadhesive composed only of bio-based ingredients has a $22 \%$ lower life cycle impact than the adhesive from petrochemical origin. Arias et al. [43] have environmentally analyzed the production of four different bio-adhesives as alternatives to the most conventional fossil resins used in the production of wood panels. The bio-adhesives proposed for analysis derived from different available renewable bio-polymers such as protein (soy) and lignin (Kraft and Organosolv), as well as tannin. The production systems were evaluated from a cradle-to-gate perspective using the life cycle assessment methodology, with the aim of identifying critical parameters and comparing them with fossil substitutes. Their results showed that the soy-based and tannin-based bio-adhesive had an overall better profile than fossil resins, identifying the production of polyacrylamide for the former, and the production of condensed tannin and glyoxal for the latter, as the main environmental hotspots. Yang and Rosentrater [44] explored the potential environmental impacts and economic feasibility of pressure-sensitive bioadhesive (PSA) produced from the reversible addition-fragmentation chain transfer polymerization process. A detail process model of pressure sensitive bio-adhesive was developed in order to thoroughly understand both economic and environmental impacts of this production process. Life cycle assessment results showed that the overall environmental impact of bio-adhesive was $\sim 30 \%$ lower compared to the petro-adhesive's production process.

After a qualitative comparison with the works of [42-44], it can be concluded that the epichlorohydrin/cardanol adhesive developed in the present work presents a similar or lower improvement of the environmental impact compared to the other bio-based adhesives.

\subsection{Results of the Mechanical Evaluation of the Bio Adhesive}

Figure 10 compares the mechanical properties of the neat bio-based adhesive and the CNTs-filled adhesive with the average properties of structural and nonstructural adhesives (cosmetic) taken from the literature. It is noted that in all cases the average mechanical properties of the structural adhesives are higher than those of the nonstructural adhesives. The Young's modulus of both novel adhesives is lower than the Young's modulus of the nonstructural adhesives. The tensile strength and the fracture toughness of both novel adhesives are larger than those of the structural adhesives. The LSS of aluminum and 
composite joints and the $T_{g}$ of both adhesives are in between the respective values of structural and nonstructural adhesives with the exception of the LSS of composite joints bonded with the CNTs-filled bio-based adhesive which is higher than the value of the similar joints bonded with commercial structural adhesives.

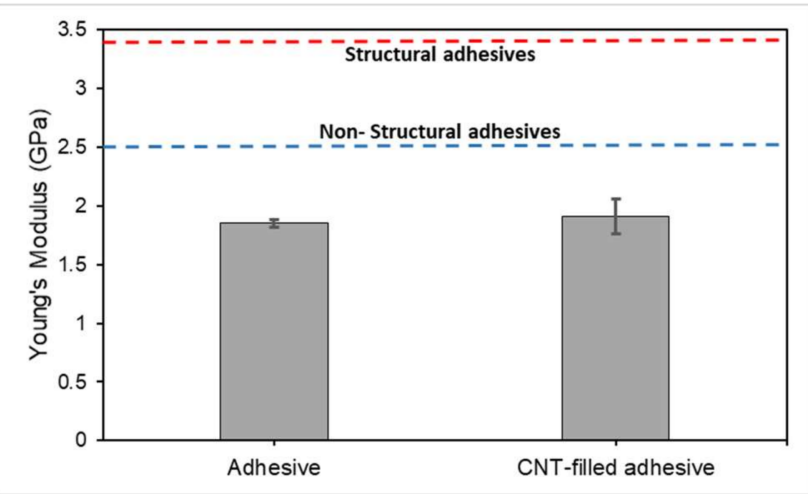

(a)

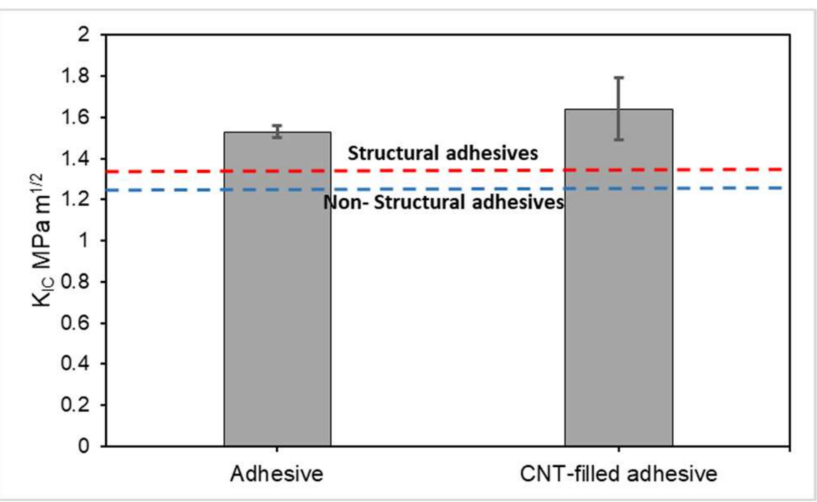

(c)

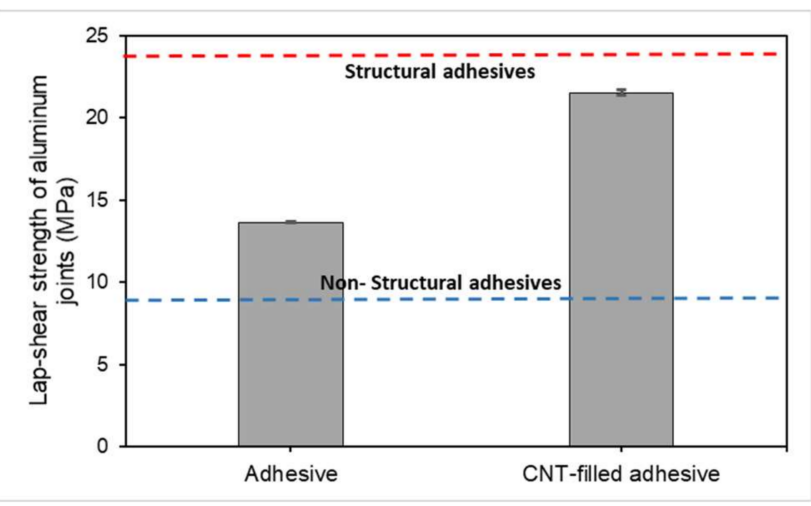

(e)

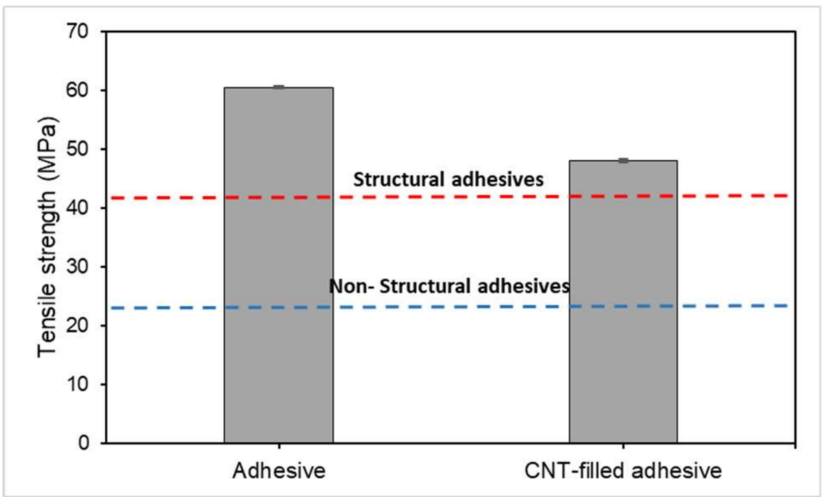

(b)

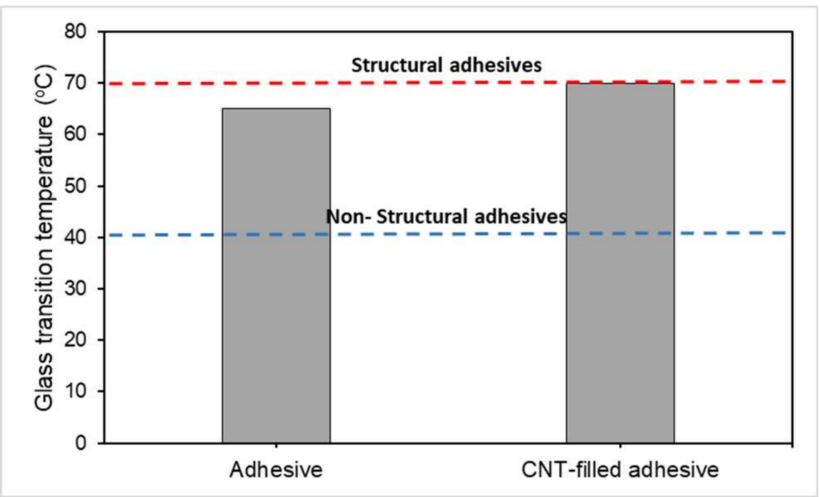

(d)

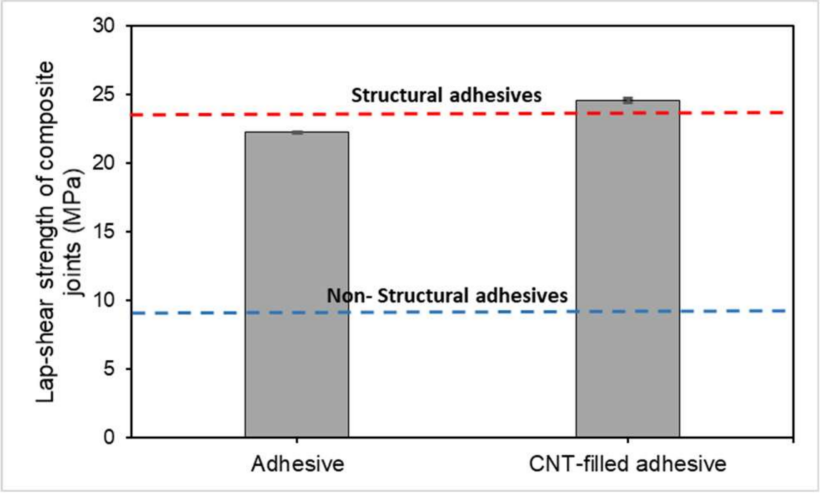

(f)

Figure 10. Comparison of mechanical properties of the neat and CNTs-filled bio-based adhesive with the average properties of structural and nonstructural (cosmetic) adhesives. (a) Young's modulus: five specimens were tested, (b) tensile strength: five specimens were tested, (c) $K_{I C}$ : three specimens were tested, (d) glass transition temperature: one specimen was tested, (e) lap-shear strength of aluminum joints: five specimens were tested, (f) lap-shear strength of composite joints: specimens were tested.

\section{Conclusions}

In this study, a two-stage final evaluation of a novel bio-based adhesive in a neat and a CNT-filled form was performed. The first stage comprised an LCA and a cost analysis. The results show that the neat bio-based adhesive had overall a lower environmental impact 
compared to a commercial reference epoxy resin as it led to lower values of all potentials except for the POCP and the EP. The addition of CNTs into the adhesive increased its environmental impact as it led to a significant increase of the GWP and the greenhouse effect. The negative effect was enhanced with increasing the CNTs content; the addition of $1 \mathrm{wt} \%$ CNTs led to the same levels of environmental impact with the epoxy reference resin. Furthermore, the new bio-based adhesive had a significantly lower production cost than the reference epoxy resin (77\%). However, this advantage also started to diminish when CNTs were added. In the second stage, a detailed evaluation of the mechanical properties of both novel adhesives was performed through a comparison with average property values of structural and nonstructural adhesives. It was found that the neat and the CNT-filled biobased adhesives had a low Young's modulus and high strength properties and they can be used for all cosmetic applications. Moreover, the CNT-filled adhesive can be also used for some structural applications which do not require high-stiffness and high-strength joining.

Author Contributions: Conceptualization, K.T. and V.T.; methodology, K.T.; validation, K.T.; investigation, K.T. and V.T.; resources, K.T.; data curation, V.T.; writing-original draft preparation, K.T. and V.T.; writing-review and editing, K.T.; supervision, K.T. All authors have read and agreed to the published version of the manuscript.

Funding: This research received no external funding.

Informed Consent Statement: Not applicable.

Conflicts of Interest: The authors declare no conflict of interest.

\section{References}

1. Cavalcanti, W.; Brune, K.; Noeske, M.; Tserpes, K.; Ostachowicz, W.; Schlag, M. (Eds.) Adhesive Bonding of Aircraft Composite Structures: Non-Destructive Testing and Quality Assurance Concepts; Springer Nature: Berlin/Heidelberg, Germany, 2021.

2. Pantelakis, S.; Tserpes, K. (Eds.) Revolutionizing Aircraft Materials and Processes; Springer Nature: Berlin/Heidelberg, Germany, 2020.

3. Bachmann, J.; Yi, X.; Tserpes, K.; Sguazzo, C.; Barbu, L.; Tse, B.; Soutis, C.; Ramón, E.; Linuesa, H.; Bechtel, S. Towards a Circular Economy in the Aviation Sector Using Eco-Composites for Interior and Secondary Structures. Results and Recommendations from the EU/China Project ECO-COMPASS. Aerospace 2021, 8, 131. [CrossRef]

4. Kreibich, U.T.; Marcantonio, A.F. New Developments in Structural Adhesives for the Automotive Industry. J. Adhes. 1987, 22, 153-165. [CrossRef]

5. Kocí, V.; Loubal, T. LCA of liquid epoxy resin produced based on propylene and on glycerin. Acta Environ. Univ. Comen. 2012, 20, 62-67.

6. Kočí, V.; Picková, E. Life cycle perspective of liquid epoxy resin use in the automotive industry. Pol. J. Environ. Stud. 2019, 29, 653-667. [CrossRef]

7. Parameswaranpillai, J.; Vijayan, D. Life Cycle Assessment (LCA) of Epoxy-Based Materials. In Micro and Nanostructured Epoxy/Rubber Blends; Sabu, T., Sinturel, C., Raju, T., Eds.; John Wiley \& Sons: Hoboken, NJ, USA, 2014.

8. Francis, R. (Ed.) Recycling of Polymers: Methods, Characterization and Applications; John Wiley \& Sons: Hoboken, NJ, USA, 2016.

9. Feih, S.; Boiocchi, E.; Mathys, G.; Mathys, Z.; Gibson, A.; Mouritz, A. Mechanical properties of thermally-treated and recycled glass fibres. Compos. Part B Eng. 2011, 42, 350-358. [CrossRef]

10. Hyde, J.R.; Lester, E.; Kingman, S.; Pickering, S.; Wong, K.H. Supercritical propanol, a possible route to composite carbon fibre recovery: A viability study. Compos. Part A Appl. Sci. Manuf. 2006, 37, 2171-2175. [CrossRef]

11. Pérez, R.L.; Ayala, C.E.; Opiri, M.M.; Ezzir, A.; Li, G.; Warner, I.M. Recycling Thermoset Epoxy Resin Using Alkyl-MethylImidazolium Ionic Liquids as Green Solvents. ACS Appl. Polym. Mater. 2021, 3, 5588-5595. [CrossRef]

12. Sukanto, H.; Raharjo, W.W.; Ariawan, D.; Triyono, J.; Kaavesina, M. Epoxy resins thermosetting for mechanical engineering. Open Eng. 2021, 11, 797-814. [CrossRef]

13. Elghazzaoui, H. Contribution à L'étude de la Dégradation des Composites Carbone/Époxy par Solvolyse Dans l'eau Subcritique et Supercritique en Vue de Leur Recyclage. Ph.D. Thesis, Université de Nantes, Nantes, France, 2012.

14. Onwudili, J.A.; Yildirir, E.; Williams, P.T. Catalytic Hydrothermal Degradation of Carbon Reinforced Plastic Wastes for Carbon Fibre and Chemical Feedstock Recovery. Waste Biomass Valorization 2013, 4, 87-93. [CrossRef]

15. Chen, N.; Zeng, Q.; Lin, Q.; Rao, J. Development of defatted soy flour based bio-adhesives using Viscozyme L. Ind. Crop. Prod. 2015, 76, 198-203. [CrossRef]

16. Gu, K.; Huang, J.; Li, K. Preparation and evaluation of particleboard bonded with a soy flour-based adhesive with a new curing agent. J. Adhes. Sci. Technol. 2013, 27, 2053-2064. [CrossRef] 
17. Luo, J.; Luo, J.; Li, X.; Li, K.; Gao, Q.; Li, J. Toughening improvement to a soybean meal-based bio-adhesive using an interpenetrating acrylic emulsion network. J. Mater. Sci. 2016, 51, 9330-9341. [CrossRef]

18. Lei, H.; Du, G.; Wu, Z.; Xi, X.; Dong, Z. Cross-linked soy-based wood adhesives for plywood. Int. J. Adhes. Adhes. 2014, 50, 199-203. [CrossRef]

19. Ceseracciu, L.; Heredia-Guerrero, J.; Dante, S.; Athanassiou, A.; Bayer, S. Robust and biodegradable elastomers based on corn starch and polydimethylsiloxane (PDMS). ACS Appl. Mater. Interfaces 2015, 18, 3742-3753. [CrossRef]

20. Khanjanzadeh, H.; Behrooz, R.; Bahramifar, N.; Pinkl, S.; Gindl-Altmutter, W. Application of surface chemical functionalized cellulose nanocrystals to improve the performance of UF adhesives used in wood based composites-MDF type. Carbohydr. Polym. 2019, 206, 11-20. [CrossRef]

21. Scarica, C.; Suriano, R.; Levi, M.; Turri, S.; Griffini, G. Lignin Functionalized with Succinic Anhydride as Building Block for Biobased Thermosetting Polyester Coatings. ACS Sustain. Chem. Eng. 2018, 6, 3392-3401. [CrossRef]

22. Rathi, S.; Saka, R.; Domb, A.J.; Khan, W. Protein-based bioadhesives and bioglues. Polym. Adv. Technol. 2019, 30, 217-234. [CrossRef]

23. Clark, R.A. Fibrin sealant in wound repair: A systematic survey of the literature. Expert Opin. Investig. Drugs 2000, 9, 2371-2392. [CrossRef] [PubMed]

24. Zhang, W.; Yu, X.; Li, Y.; Su, Z.; Jandt, K.D.; Wei, G. Protein-mimetic peptide nanofibers: Motif design, self-assembly synthesis, and sequence-specific biomedical applications. Prog. Polym. Sci. 2018, 80, 94-124. [CrossRef]

25. Tzatzadakis, V.; Tserpes, K. Production of a novel bio-based structural adhesive and characterization of mechanical properties. J. Adhes. 2021, 97, 936-951. [CrossRef]

26. Tzatzadakis, V.; Tserpes, K. Experimental characterization of the hygrothermal ageing effects on the bulk mechanical properties and lap-shear strength of the novel bio-based epichlorohydrin/cardanol adhesive. J. Adhes. 2020, 97, 1-19. [CrossRef]

27. Tserpes, K.; Tzatzadakis, V. Synthesis and Experimental Characterization of a MWCNT-Filled Bio-Based Adhesive. Aerospace 2021, 8, 26. [CrossRef]

28. Spolchemie.cz. [Internet]. 2020. Available online: https://www.spolchemie.cz/media/c2786f0c-de6f-4393-b1cc-e01520878fd3 /Jy_j6w / 4distributors/EPD\%20LER\%20A\%20certification\%20websites.pdf (accessed on 3 November 2020).

29. Environmental Labels and Declarations-Type III Environmental Declarations-Principles and Procedures; EN ISO 14025; International Standard Organisation (ISO): Geneva, Switzerland, 2006.

30. ISO 14040. Environmental Management-Life Cycle Assessment-Principles and Framework (ISO 14040: 2006); CEN (European Committee for Standardisation): Brussels, Belgium, 2006.

31. Matanza, A.; Vargas, G.; Leon, I.; Pousse, M.; Salmon, N.; Marieta, C. Life cycle analysis of standard and high-performance cements based on carbon nanotubes composites for construction applications. World SB 2014, 4, 28-30.

32. Upadhyayula, V.K.; Meyer, D.E.; Curran, M.A.; Gonzalez, M. Life cycle assessment as a tool to enhance the environmental performance of carbon nanotube products: A review. J. Clean. Prod. 2012, 26, 37-47. [CrossRef]

33. Singh, A.; Agboola, A.; Yaws, C.L.; Lou, H.H.; Pike, R.W.; Li, X.; Hopper, J.R. Environmental Impact Assessment for Potential Continuous Processes for the Production of Carbon Nanotubes. Am. J. Environ. Sci. 2008, 4, 522-534. [CrossRef]

34. Khanna, V.; Bakshi, B.; Lee, L. Carbon nanofiber production: Life cycle energy consumption and environmental impact. J. Ind. Ecol. 2008, 12, 394-410. [CrossRef]

35. Katsiropoulos, C.V.; Loukopoulos, A.; Pantelakis, S.G. Comparative Environmental and Cost Analysis of Alternative Production Scenarios Associated with a Helicopter's Canopy. Aerospace 2019, 6, 3. [CrossRef]

36. electricityMap. Live $\mathrm{CO}_{2}$ Emissions of Electricity Consumption. [Internet]. Available online: https://app.electricitymap.org/map (accessed on 3 November 2020).

37. Burchardt, B. Advances in polyurethane structural adhesives. In Advances in Structural Adhesive Bonding; Elsevier: Amsterdam, The Netherlands, 2010; pp. 35-65.

38. Hollaway, L. Key issues in the use of fibre reinforced polymer (FRP) composites in the rehabilitation and retrofitting of concrete structures. In Service Life Estimation and Extension of Civil Engineering Structures; Elsevier: Amsterdam, The Netherlands, 2011; pp. 3-74.

39. Araldite Industrial Adhesives-Home [Internet]. Aralditeadhesives.com. 2020. Available online: http:/ /aralditeadhesives.com/ index.php?option=com_content\&view=article\&id=48\&Itemid=142\&lang=en (accessed on 14 November 2020).

40. LOCTITE Solutions [Internet]. Henkel-adhesives.com. 2020. Available online: https://www.henkel-adhesives.com/us/en/ about/our-brands/loctite.html (accessed on 14 November 2020).

41. Overview of Materials for Epoxy Adhesive [Internet]. Matweb.com. 2020. Available online: http://www.matweb.com/search/ datasheettext.aspx?matguid=c1ec1ad603c74f628578663aaf44f261 (accessed on 14 November 2020).

42. McDevitt, J.E.; Grigsby, W.J. Life Cycle Assessment of Bio- and Petro-Chemical Adhesives Used in Fiberboard Production. J. Polym. Environ. 2014, 22, 537-544. [CrossRef]

43. Arias, A.; González-García, S.; González-Rodríguez, S.; Feijoo, G.; Moreira, M.T. Cradle-to-gate Life Cycle Assessment of bio-adhesives for the wood panel industry. A comparison with petrochemical alternatives. Sci. Total Environ. 2020, $738,140357$. [CrossRef]

44. Yang, M.; Rosentrater, K.A. Life Cycle Assessment and Techno-Economic Analysis of Pressure Sensitive Bio-Adhesive Production. Energies 2019, 12, 4502. [CrossRef] 